\title{
Fermentation and antimicrobial characteristics of Lactobacillus plantarum and Candida tropicalis from Nigerian fermented maize (akamu)
}

\author{
Patience C. Obinna-Echem ${ }^{\mathrm{a}} \mathrm{b}^{*}$, Victor Kuri $^{\mathrm{a}}$, And Jane Beal ${ }^{\mathrm{a}}$ \\ a School of Biological Sciences, Faculty of Science and Environment, Plymouth University, PL4 8AA, \\ Plymouth, UK \\ ${ }^{\mathrm{b}}$ Food Science and Technology, Rivers State University of Science and Technology, P.M.B. 5080. Port \\ Harcourt, Rivers State, Nigeria \\ ${ }^{*}$ Corresponding author \\ patience.obinna-echem@plymouth.ac.uk \\ TEL: +441752584600
}

Received: 8 October 2013; Published online: 18 October 2014

\begin{abstract}
This study investigated the ability of Lactobacillus plantarum strains (NGL5 and NGL7) and Candida tropicalis (NGY1) previously identified from akamu-a Nigerian fermented maize food with probiotic L. plantarum LpTx and Saccharomyces boulardii SB20 to ferment ground maize slurries based on pH, acidity, microbial biomass, levels of sugars and organic acids, and their antimicrobial activity against Salmonella enterica serovar Enteritidis NCTC 5188, Escherichia coli NCTC 11560, Bacillus cereus NCIMB 11925, Staphylococcus aureus NCTC 3750 and Listeria monocytogenes NCTC 7973 using an agar spot assay. L. plantarum strains either as single or mixed starter cultures with the yeasts had growth rates $\geq 0.15 \mathrm{~h}^{-1}$, with $\mathrm{pH}$ significantly $(\mathrm{p} \leq 0.05)$ decreased to $\leq 3.93$ after $12 \mathrm{~h}$ and then to $\leq 3.52$ after $72 \mathrm{~h}$ and lactic acid $>84 \mathrm{mmol} \mathrm{L} \mathrm{L}^{-1}$. The yeasts had growth rates $\geq 0.18 \mathrm{~h}^{-1}$ but $\mathrm{pH}$ was $\geq 4.57$ with lactic acid levels $\leq 20.23 \mathrm{mmol} \mathrm{L}^{-1}$ after $72 \mathrm{~h}$ in the single culture fermentation. There was no inhibition in modified MRS agar: $0.2 \%$ glucose and $0.2 \%$ glucose without Tween 80 . Inhibition halos in MRS agar varied from 10.6 to $23.9 \mathrm{~mm}$. S. bourladii was more inhibitory towards L. monocytogenes $(8.6 \mathrm{~mm})$ and B. cereus $(5.4 \mathrm{~mm})$ than was $C$. tropicalis $(1.1$ and $3.3 \mathrm{~mm}$ for L. monocytogenes NCTC 7973 and $B$. cereus NCIMB 11925 respectively) $(0.9 \mathrm{~mm})$ in malt extract agar. This study showed that $C$. tropicalis was less inhibitory to the pathogens while antimicrobial activities of the L. plantarum strains were mainly due to acidity and the L. plantarum strains either as single or mixed cultures with the yeasts demonstrated strong fermentation ability, with significant decrease in $\mathrm{pH}$ which is vital in the choice of starter for product safety.
\end{abstract}

Keywords: L. plantarum; C. tropicalis; Fermentation; Ground maize slurry; Acidity; Antimicrobial activities; Pathogens

\section{Introduction}

Fermentation is one of the oldest food preparation methods considered as safe and acceptable for improving the quality and safety of foods. Traditional fermentation technologies were based on a natural process, whereby wet foodstuffs undergo microbial degradation, and when the food is edible it was termed fermented (Lee, 2009). Over the years, the fermentation process has developed such that organic substrates are now converted into more desirable substances through 
the action of enzymes or microorganisms under controlled conditions to achieve several specific important functions (Towo, Matuschek, \& Svanberg, 2006). In most African countries fermented cereal-based foods play an important role in the nutrition of infants and young children, as major infant complementary foods, and form an integral part of the main meal for adults. The traditional techniques of cereal food production depend on spontaneous or back-slop fermentation (the use of some portion of previously fermented product as inoculum to accelerate fermentation). Spontaneous fermentation of cereal-based foods is borne out of competitive activities of endogenous or contaminating microorganisms and its initiation may take $24-48 \mathrm{~h}$. At the early stages of fermentation, contaminating microorganisms may increase slowly in number and compete for nutrients in order to produce metabolites (Holzapfel, 2002). The results are products of variable attributes in terms of quality and safety (Ouoba, Diawara, Jespersen, \& Jakobsen, 2007). The growth of endogenous cultures of the substrate or those from the ingredients and equipment used in production may be inevitable, even with the introduction of starter cultures of the desired microorganism. It is therefore important that the selected microbial inoculant to facilitate the process should be adaptive to the substrate from the onset of fermentation so as to prevent the growth of unwanted microorganisms to a level that would impair the product's quality.

Lactic acid bacteria (LAB) and yeast occur as part of the natural microbial population in spontaneously fermented foods and as starter cultures in the food and beverage industry (Shetty \& Jespersen, 2006). In a recent study by ObinnaEchem, Kuri, and Beal (2014), the LAB population of a selected Nigerian traditional fermented maize food called akamu was found to be dominated by strains of Lactobacillus plantarum, $L$. fermentum, L. delbrueckii subsp. bulgaricus and $L$. helveticus while the identified yeasts included Candida tropicalis, C. albicans, Clavispora lusitaniae and Saccharomyces paradoxus. The presence of LAB and yeasts have also been associated with many other fermented maize doughs and porridges (Akinrele, 1970; Edema \& Sanni, 2008; Omemu, Oyewole, \& Bankole, 2007; Teniola
\& Odunfa, 2001). Amylolytic LAB breakdown starches to simple sugars which are favourable for LAB growth. The simple sugars are then converted to organic acids that create the acid environment which is known to improve product stability and safety. Although yeast's main function has been related to the production of alcohol and aroma compounds that impact significantly on food quality parameters such as taste, texture, odour and nutritive value (Aidoo, Nout, \& Sarkar, 2006; Annan, Poll, Sefa-Dedeh, Plahar, \& Jakobsen, 2003), Omemu et al. (2007) reported that yeasts associated with maize fermentation for ogi production produced several extracellular enzymes and the amylolytic activities of some of the yeasts were implicated in the breakdown of maize starch to simple sugars for other fermenting microorganisms.

Contamination of cereal-based complementary foods has been implicated in diarrhoeal episodes among infants and children $<5$ years in developing countries. Globally, diarrhoea causative agents are broad and include bacteria, viruses and parasitic agents. Pathogenic strains of Escherichia coli, Shigella spp., Salmonella spp., Vibrio cholera and Campylobacter spp. are the principal bacterial agents. The viral agents include Hepatitis A and E, Norovirus (calicivirus), Adenovirus (serotype 40/41), Astrovirus, Cytomegalovirus and Rotavirus. Protozoa such as Giardia lamblia, Entamoeba histolytica, Cryptosporidium spp. and Helminths such as Strongyloides stercoralis, Angiostrongylus costaricensis, Schistosoma mansoni and S. japonicum constitute the parasitic agents (Farthing et al., 2013; Motarjemi, 2002). The pathogenic bacteria and parasites are more prevalent in the developing countries than viruses (Farthing et al., 2013). Contamination of infant complementary foods may occur, through various sources, before, during and after food preparation. Fermentation of cereal-based foods has been reported to provide an antagonistic environment against pathogenic bacteria due to the production of organic acids that lower $\mathrm{pH}$ to a level inhibitory to some pathogenic organisms. However, some studies have been able to isolate relevant foodborne pathogens such as Bacillus cereus, Clostridium perfringens, Aeromonas spp., Staphylococcus aureus and some $E$. coli in fermented cereal foods 
(Kunene, Hastings, \& von Holy, 1999; Nyatoti, Mtero, \& Rukure, 1997; Wakil, Onilude, Adetutu, \& Ball, 2008).

Therefore this study was aimed at determining:

- the fermentation characteristics of L. plantarum strains (NGL5 and NGL7) and Candida tropicalis (NGY1) isolated from traditional akamu samples and their probiotic counterpart: L. plantarum Lptx and Saccharomyces bourladii SB20 for suitability as starter cultures in akamu fermentation based on $\mathrm{pH}$, acidity and levels of sugars and organic acids; and

- the antimicrobial activity of L. plantarum strains and yeasts against five relevant foodborne pathogens: Salmonella enterica serovar Enteritidis NCTC 5188, E. coli NCTC 11560, B. cereus NCIMB 11925, $S$. aureus NCTC 3750 and L. monocytogenes NCTC 7973).

\section{Materials and Methods}

\subsection{Ground maize and fermentation slurry}

Ground organic maize (L1530) was obtained from the Health Food Shop, Rickard Lane's, Plymouth City Centre, UK. About $50 \pm 0.01 \mathrm{~g}$ of the flour was weighed into cellophane bags, sealed and irradiated with ${ }^{60} \mathrm{Co}$ at $25.88 \pm 0.79 \mathrm{kGy}$ (Becton, Dickinson and Company, Plymouth, UK). The slurry for fermentation was thereafter prepared by adding $100 \mathrm{~mL}$ of sterile distilled water containing the microbial inoculant. To verify the sterility of the irradiated sample, some un-inoculated slurries were kept in an incubator (Swallow Incubators, LTE Scientific Ltd, Green field, Oldham, UK) at $30^{\circ} \mathrm{C}$ without agitation. The slurries after 0 to 7 days were checked for microbial growth by streak plating on Nutrient agar plates followed by incubation at 30 and $37^{\circ} \mathrm{C}$ for $3-7$ days. The sterility of the irradiated samples was confirmed when no microbial growth was observed in the incubated plates. Although maize grains for akamu production would not ordinarily be irradiated, irradiation was used in this study to ensure that the characteristics being evaluated were that of the inoculated starter cultures.

\subsection{Microbial inoculant}

\section{LAB and yeasts}

The LAB and yeast cultures used were L. plantarum strains (NGL5 and NGL7) and C. tropicalis (NGY1), previously identified from a traditional akamu sample (M3) obtained from Rivers State, Nigeria using PCR and sequencing analysis by Obinna-Echem et al. (2014) and their probiotic counterpart: L. plantrum LpTx isolated from a probiotic food supplement capsule obtained from the Health Food Shop in Plymouth City Centre, UK, and S. boulardii SB20 from Lalleman Levucell cultures, Nottingham, UK.

\section{Pathogens}

Antimicrobial activities, using the agar spot method, were assayed against five foodborne pathogens: B. cereus NCIMB 11925, E. coli NCTC 11560, L. monocytogenes NCTC 7973, Salmonella enterica serovar Enteritidis NCTC 5188, and S. aureus NCTC 3750 obtained from stock cultures in the microbiological laboratory of Plymouth University, UK.

\subsection{Inoculant preparation}

Generally, the microorganisms were cultivated by streaking on the appropriate agar media, with incubation at the organisms' optimum growth conditions as follows: the L. plantarum strains were cultivated on de Man, Rogosa and Sharpe (MRS) agar and incubated at $37^{\circ} \mathrm{C}$ for $24 \mathrm{~h}$; the yeasts were cultivated on malt extract agar and incubated at $25^{\circ} \mathrm{C}$ for $48 \mathrm{~h}$; and the pathogens were cultivated on Nutrient agar and incubated at $37^{\circ} \mathrm{C}$ for $24 \mathrm{~h}$, except for $B$. cereus that was incubated at $30^{\circ} \mathrm{C}$ for $24 \mathrm{~h}$. MRS, Malt extract and Nutrient broths were used for broth cultures of the $\mathrm{LAB}$, yeasts and the pathogens respectively. A distinct colony of the respective microorganisms from the agar plate culture was inoculated into $10 \mathrm{~mL}$ of the appropriate broth media and incubated at $37^{\circ} \mathrm{C}$ without agitation for $18-20$ 
h for the L. plantarum strains and the pathogens except for $B$. cereus that was incubated at $30^{\circ} \mathrm{C}$ while the yeasts were incubated at $25^{\circ} \mathrm{C}$ without agitation for $40 \mathrm{~h}$. Cultures were harvested by centrifugation (Hettich Zentrifugen Rotina 46 $\mathrm{S}$, Tuttlingen, Germany) at $4000 \times \mathrm{g}$ for $10 \mathrm{~min}$ and washed twice in phosphate buffered saline (PBS) ( $\mathrm{pH} \mathrm{7.3 \pm 0.2)} \mathrm{and} \mathrm{re-suspended} \mathrm{in} \mathrm{PBS}$ such that $1 \mathrm{~mL}$ of inoculum produced $10^{9}, 10^{7}$ and $10^{6} \mathrm{CFU} \mathrm{mL} \mathrm{mL}^{-1}$ for the LAB, the yeasts and the pathogens respectively. The media and the diluent used were obtained from Oxoid Limited (Basingstoke, Hampshire, UK).

\subsection{Fermentation characteristics}

\section{Inoculation and fermentation of ground maize slurry}

The single culture fermentation utilized $1 \mathrm{~mL}$ of the microbial inoculum added to $100 \mathrm{~mL}$ of sterile distilled water that was thoroughly mixed with $50 \pm 0.01 \mathrm{~g}$ irradiated ground maize while the mixed culture fermentation used an equal volume $(1 \mathrm{~mL})$ of a strain of the L. plantarum and the specified yeast. $18 \mathrm{ml}$ of inoculated slurries were dispensed into sterile transparent $50 \mathrm{~mL}$ plastic pots with lids and incubated aerobically at $30^{\circ} \mathrm{C}$ without agitation for $72 \mathrm{~h}$. Using $1 \mathrm{~mL}$ graduated sterile disposable plastic pipettes, samples were aseptically withdrawn after $0,6,12,24,48$, and $72 \mathrm{~h}$ of fermentation for determination of $\mathrm{pH}$, titratable acidity, microbial count, organic acids and sugars. Samples for determination of organic acids and sugars were preserved in eppendorff tubes at $-80^{\circ} \mathrm{C}$ until needed. Un-inoculated samples served as controls.

\section{Determination of $\mathrm{pH}$ and Titratable acidity (TTA) of the fermentation}

The $\mathrm{pH}$ of $1 \mathrm{~mL}$ of sample in $10 \mathrm{~mL}$ of sterile distilled water was determined with a $\mathrm{pH}$ meter (Accumet $^{R}$ AB10, Fisher Scientific, Loughborough, UK). The TTA was determined titrimetrically as described by Obinna-Echem et al. (2014).

\section{Determination of organic acids and sugars}

\section{Reagents and standards}

The chemicals used were either of analytical or high performance liquid chromatography (HPLC) grade. Concentrated $\mathrm{H}_{2} \mathrm{SO}_{4}$, ethanol and methanol were purchased from Fisher Scientific, Loughborough, UK. The standard sugars (glucose, fructose, sucrose and maltose) and organic acids (acetic, butyric, lactic and propionic acid) were supplied by Sigma Aldrich, Gillingham Dorset, UK. Appropriate concentrations of reagents and standards were obtained by dissolving or making-up the appropriate weight or volume in deionised water purified through a Milli-Q system (Millipore Corp., Bredford, MA, USA).

\section{Instrumentation}

The organic acid composition (citric, acetic, lactic, propionic and butyric acids) of the fermented ground maize slurry was analysed using ultra high performance liquid chromatography (UHPLC), Dionex-Ultimate 3000 UHPLC+Focused (Dionex Softron GmbH, Germering, Germany). The ultra high performance liquid chromatography (UHPLC) was equipped with WPS-3000 autosampler, LPG-3400SD pump, TCC-3000 column compartment, RI-101 refractive index detector and MWD-3000 Ultra violet detector.

\section{Sample preparation}

Samples of fermented ground maize slurries (1.5 $\mathrm{mL}$ ) stored frozen in eppendorf tubes were allowed to thaw at room temperature. The samples were homogenised on a Multi-mixer (Fisher Scientific, Loughborough, UK) for $10 \mathrm{~s}$ and then centrifuged at $13000 \times \mathrm{g}$ for $20 \mathrm{~min}$ (Sanyo-MSE MSB010.CX2.5 Micro Centaur Centrifuge, Alconbury, UK). $20 \mu \mathrm{L}$ of $7 \% \mathrm{H}_{2} \mathrm{SO}_{4}$ was added to $100 \mu \mathrm{L}$ of the sample supernatant, in $400 \mu \mathrm{L}$ of Milli-Q water. Addition of the mineral acid, according to Niven, Beal, and Brooks (2004), was to shift the acid equilibrium of weak acids to the protonated form so as to help maintain the column functionality. The prepared samples were thoroughly mixed by vortexing for $5 \mathrm{~s}$, filtered through a MF-millipore microfiltre $(0.22 \mu \mathrm{m}$ pore 
size) into vials, sealed with a crimp cap $(11 \mathrm{~mm}$, Rubber/PTFE, Fisher Scientific, Loughborough, UK) and stored at $-80^{\circ} \mathrm{C}$ until needed for analysis.

\section{HPLC conditions and data analysis}

The chromatographic separation was achieved with an elution phase of degased $5 \mathrm{mmol} \mathrm{L} \mathrm{L}^{-1}$ of $\mathrm{H} 2 \mathrm{SO} 4$ in a PL Hi-Plex H Guard column 50 x $7.7 \mathrm{~mm}$ (Agilent Technologies, WaghaeuselWiesental, Germany) at a column temperature of $25^{\circ} \mathrm{C}$. The eluent was pumped at a flow rate of $0.5 \mu \mathrm{L} \mathrm{min}^{-1}$ within a pressure limit of $5-100$ bars. The injected sample volume was $20 \mu \mathrm{L}$. The sugars and organic acids were detected using Refractive Index and Ultra Violet detectors respectively. The retention times of sugar and organic acid standards were noted and used in the identification of the sample peaks. All data obtained was processed using Chromeleon ${ }^{\circledR} 7.1$ Chromatography Data System Software (Dionex Softron GmbH, Germering, Germany). Calibration curves for each sugar and organic acid were obtained from four different concentrations (100, 50,25 and $12.5 \mathrm{mmol} \mathrm{L}^{-1}$ ) of the standards stock solutions.

\subsection{Fermentation characteristics}

Ten-fold dilutions of $1 \mathrm{~mL}$ of sample slurries in $9 \mathrm{~mL}$ of PBS were prepared and plated out using the drop method by Miles, Misra, and Irwin (1938) on MRS agar supplemented with $0.01 \%$ cyclohexamide for the L. plantarum strains and on Rose Bengal Chloramphenicol Agar (RBCA) containing $0.01 \%(\mathrm{w} / \mathrm{v})$ chloramphenicol selective supplement for yeasts. The plates were incubated aerobically at $37^{\circ} \mathrm{C}$ for $24-48 \mathrm{~h}$ and $25^{\circ} \mathrm{C}$ for $48 \mathrm{~h}$ for the L. plantarum strains and yeasts respectively. The number of colony forming units per millilitre was computed as eq. 1:

$$
C F U m L^{-1}=C F U / V_{s}
$$

Where CFU represents the average number of colonies for a dilution X Dilution factor and $V_{s}$ is the volume of the sample plated.

\subsection{Antimicrobial activities}

Antimicrobial activities were determined by the agar spot test, with some modification to the method described by Majhenic, Lorberg, and Rogelj (2007). The L. plantarum strains were grown both in MRS and modified MRS agar: MRS with $0.2 \%$ glucose (MRS.2) and MRS with $0.2 \%$ glucose and without Tween 80 (MRS.2T80). Acid production was checked by the reduction of glucose while the removal of Tween 80 was to enhance any production of antimicrobial agents. Two microlitres of washed and resuspended $18 \mathrm{~h} \mathrm{~L}$. plantarum cells $\left(\mathrm{c} .10^{9} \mathrm{CFU}\right.$ $\mathrm{mL}^{-1}$ ) were spotted on the agar plates and incubated both at $37^{\circ} \mathrm{C}$ for $24 \mathrm{~h}$. Malt extract agar plates were spotted with $10 \mu \mathrm{L}$ of washed and re-suspended $48 \mathrm{~h}$ yeast cells and incubated at $25^{\circ} \mathrm{C}$ for $48 \mathrm{~h}$. Afterwards, plates were overlaid with $10 \mathrm{~mL}$ of soft Nutrient agar $\left(7.5 \mathrm{~g} \mathrm{~L}^{-1}\right)$ and inoculated with $33 \mu \mathrm{L}$ of cell suspension containing $10^{6} \mathrm{CFU} \mathrm{mL}-1$ of the respective five foodborne pathogens. The overlaid plates were incubated at the optimal growth temperature for the respective pathogens: $30^{\circ} \mathrm{C}$ for $B$. cereus and $37^{\circ} \mathrm{C}$ for the others. After $24-48 \mathrm{~h}$ of incubation, the plates were observed for inhibition zones and the diameter $(\mathrm{mm})$ of inhibition halos were measured at 3 - 4 different angles using an analogue sliding Vernier Calliper $120 \mathrm{~mm}$ (Skill Tech 5 in, Frankfurt, Germany) and the average reading was taken.

\section{7 $\quad$ Statistical analysis}

Data obtained was statistically analysed using Minitab (Release 16.0) Statistical Software English (Minitab Inc. UK). Statistical differences were evaluated by analysis of variance (ANOVA), under a general linear model, and Tukey pairwise comparisons at the $95 \%$ confidence level. The growth rates of the microorganisms were obtained using the microbial model (DMFit version 2.0) by Baranyi and Roberts (1994). 


\section{Results and Discussion}

\subsection{Fermentation characteristics}

\section{pH and Titratable acidity (TTA)}

The effect of fermentation with the L. plantarum strains, Sacch. Bourlardii SB20 and C. tropicalis on $\mathrm{pH}$ and TTA are presented in Figure 1 and Figure 2 respectively. A decrease in $\mathrm{pH}$ has been established as an important parameter for assessing how fast a process will reach conditions $(\mathrm{pH}<4.5)$ which can inhibit the growth of pathogenic organisms (Nguyen et al., 2007). The $\mathrm{pH}$ of the L. plantarum single $(\leq 3.43)$ or mixed culture fermentation with the yeasts $(\leq 3.52)$ were such that would not permit the survival of most unwanted microorganisms, while the decrease in $\mathrm{pH}$ of the yeast single culture fermentation was $\geq 4.57$. Progression in fermentation of cereal and cereal-legume mixtures has often been marked with an increase in microbial numbers, concomitant with a decrease in $\mathrm{pH}$ and an increase in TTA (Mugula, Narvhus, \& Sorhaug, 2003; Teniola \& Odunfa, 2002; Wakil et al., 2008). This was observed with the L. plantarum strains, either as a single or mixed starter cultures with the yeasts. The $\mathrm{pH}(5.59-5.23)$ and TTA $(0.09-0.24 \%)$ of the control samples did not change significantly $(\mathrm{p} \leq 0.05)$. However, this was expected as the maize flour samples were irradiated and sterile distilled water was used in the fermentation. Lactic acid was mostly responsible for the lowering of $\mathrm{pH}$ in the fermentations and there was no detectable level of microorganisms in the control for any notable change. The TTA $(\leq 0.33 \%)$ of the yeast single culture fermentation was significantly $(\mathrm{p} \leq 0.05)$ lower than that of the $L$. plantarum single $(\geq 1.05 \%)$ and in the mixed culture fermentation $(\leq 0.90 \%)$ but did not show any significant difference from that of the control. This may also be attributed to the little or no lactic acid production by the yeasts.

\section{Levels of lactic acid, ethanol and sugars}

Table 1 shows the lactic acid levels of the fermentation. Bacteria produce organic acids from the fermentation of carbohydrate and over time decreased the amount of sugars: glucose, fructose and maltose (Table 2, Table 3 and Table 4 respectively) detected in the fermentation by the selected L. plantarum strains. The initial glucose level increased within the first $6 \mathrm{~h}$ of fermentation while the maltose and fructose levels were depleted. This may imply the breakdown of complex carbohydrate first to the simple sugar: glucose before its utilization. This may also explain the higher lactic acid levels in the samples as compared to the initial glucose levels since homofermenters like $L$. plantarum are capable of producing $2 \mathrm{~mol}$ of lactic acid from $1 \mathrm{~mol}$ of glucose (Reddy, Altaf, Naveena, Venkateshwar, \& Kumar, 2008). Although, glucose levels of $\geq 26.88 \mathrm{mmol} \mathrm{L}^{-1}$ were detected in the $L$. plantarum single culture fermentation after 72 $\mathrm{h}$, it was completely depleted after $24 \mathrm{~h}$ in the yeast single and mixed culture fermentation with the L. plantarum strains. One would logically think that the lactic acid levels in fermentation, where all the glucose has been utilized, would be significantly greater. However, the lactic acid concentration of the single $L$. plantarum culture fermentation was significantly $(\mathrm{p} \leq 0.05)$ greater than the yeast mixed culture fermentation, with particular reference to the fermentation with $S$. boulardii. This indicates competition for glucose in the mixed culture fermentation with the yeasts and its metabolism to the respective fermentative microorganism's metabolic by product. The L. plantarum strains in the presence of more fermentable glucose after $72 \mathrm{~h}$ could survive longer in the single culture fermentation and thus prolong the keeping quality of the product.

In addition to lactic acid, the other organic acids investigated in this study were citric, acetic, propionic and butyric acids (data not shown). Although, citric, acetic, pyruvic, succinic, formic and propionic acids had been identified in different LAB fermented cereal foods (Banigo \& Muller, 1972; Gobbetti \& Corsetti, 1997; Muyanja, Narvhus, Treimo, \& Langsrud, 2003), the L. plantarum strains in this study produced mainly lactic acid. Although, the fructose and maltose levels of the control sample were fairly constant (Table 3 and Table 4 respectively), the observed significant increase in glucose level could be attributed to the hydrolysis of the maize starch to its basic component as 


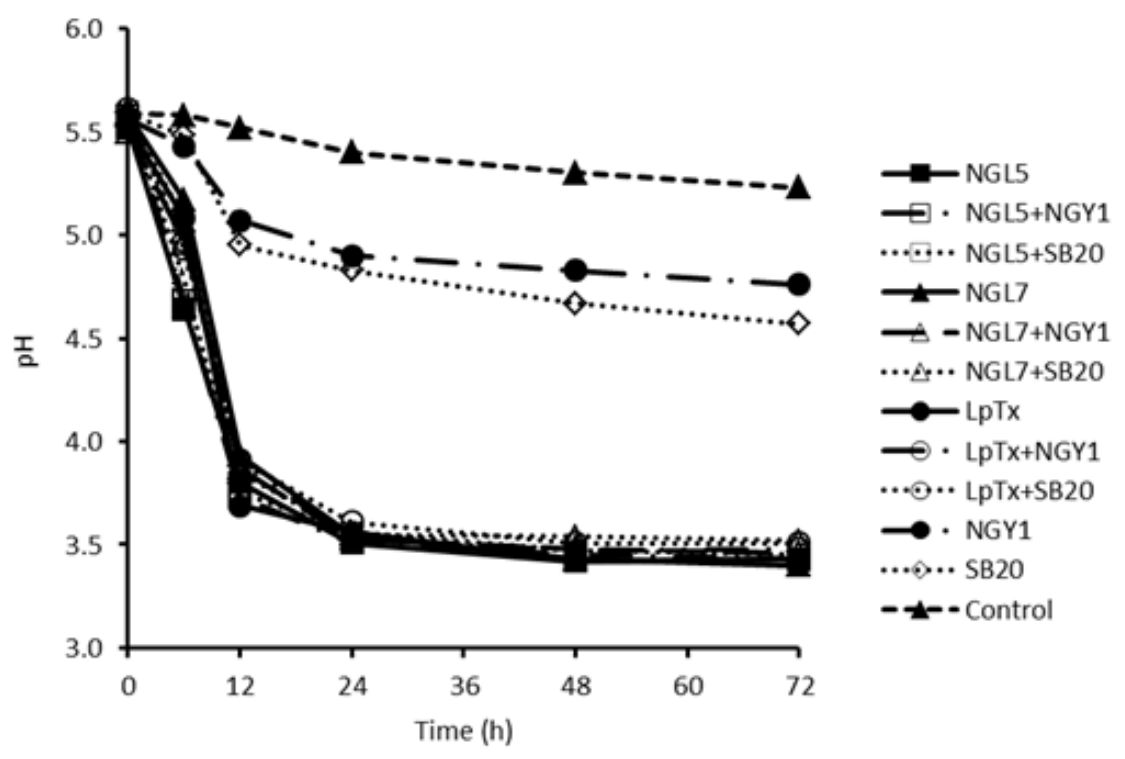

Figure 1: pH of ground maize slurry fermented with single or mixed cultures of Lactobacillus plantarum strains (NGL5, NGL7 and LpTx) and yeasts (Candida tropicalis -NGY1 and Saccharomyces boulardii SB20)

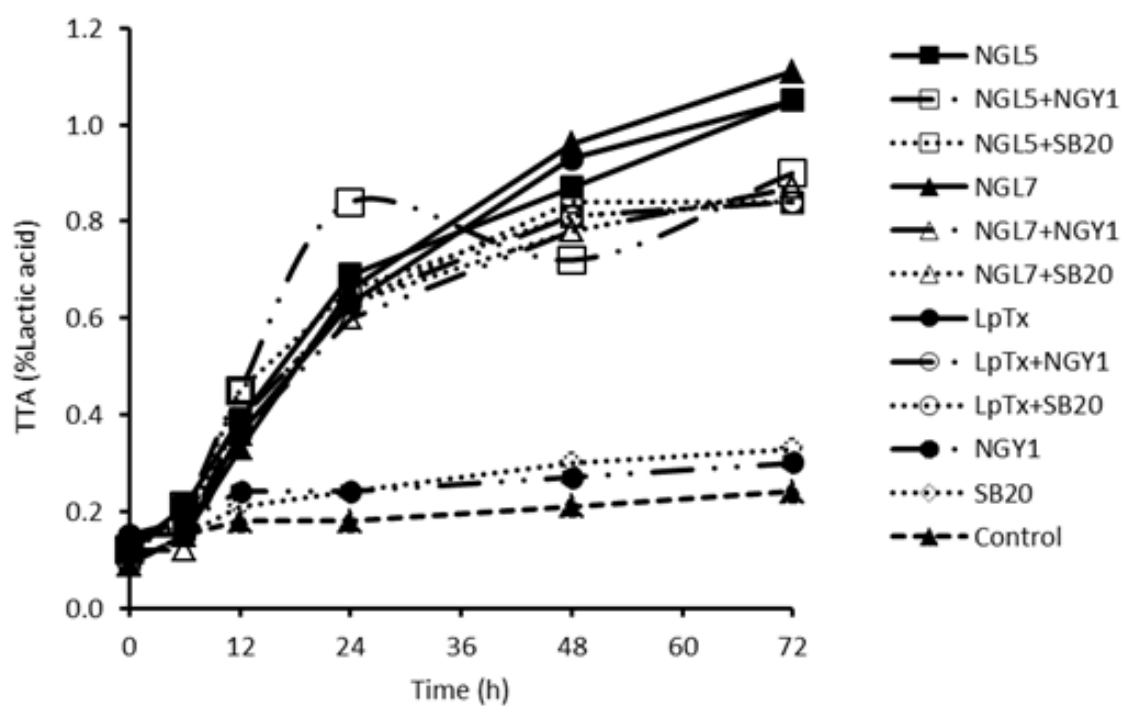

Figure 2: Titratable acidity (\%Lactic acid) of ground maize slurry fermented with single or mixed cultures of Lactobacillus plantarum strains (NGL5, NGL7 and LpTx) and yeasts (Candida tropicalis NGY1 and Saccharomyces boulardii SB20) 
glucose by the endogenous grain amylases under the wet conditions.

The levels of ethanol detected in the fermentation are presented in Table 5. There was no ethanol detected in the samples fermented by the single and the mixed cultures of $L$. plantarum strains and $C$. tropicalis except for LpTx+NGY1 which had an ethanol level of 14.8 mmol $\mathrm{L}^{-1}$ after $24 \mathrm{~h}$. Ethanol production in the yeast single culture fermentation was significantly $(\mathrm{p} \leq 0.05)$ higher than the mixed culture fermentation. The highest ethanol level was detected in $S$. boulardii SB20 single culture fermentation. Higher ethanol levels were also detected in the mixed culture fermentation with the L. plantarum strains. Ethanol production may not be needed in the fermentation for infant and children feeding. The absence and/or very low level of ethanol production in the L. plantarum strains and $C$. tropicalis mixed culture fermentation was indicative of the dominant activities of the LAB in the fermentation, as well as a contamination free process. The role of yeast in the flavour of fermented maize products has been reported by Annan et al. (2003), Mugula et al. (2003) and Omemu et al. (2007). Therefore, the characteristic of $C$. tropicalis to grow in the fermentation, with little or no ethanol production, could be important in akamu production as the product flavour is an important sensory property. The ability of yeast to utilise certain bacterial metabolites as carbon sources (Akinrele, 1970; Leroi \& Pidoux, 1993) and the competition for utilizable sugars could be contributory to the reduction in the lactic acid content of the mixed culture fermentation.

\section{Microbial growth}

The viable counts of the $L$. plantarum strains and yeasts: C. tropicalis and S. boulardii SB20 in the fermentations are respectively shown in Figure 3 and Figure 4, while their growth model parameters are presented in Table 6 and Table 7 respectively. A typical pattern of microbial growth in a closed system was obtained. The main phases of growth observed were the log, decelerating and the stationary phases. The viable counts reached a maximum of approximately $10^{9}$ $\mathrm{CFU} \mathrm{mL}^{-1}$ after $24 \mathrm{~h}$ and then declined before reaching fairly constant values towards the end of fermentation, thus depicting the decelerating and the stationary phases. Although, glucose levels $>26 \mathrm{mmol} \mathrm{L}^{-1}$ were detected after the peak viable count and towards the end of fermentation, the L. plantarum strains in a close fermentation system for $72 \mathrm{~h}$ may not be able to continue to grow exponentially with the accumulation of lactic acid and other less abundant inhibitor products of cell metabolism. Furthermore, the exhaustion of utilisable carbon dioxide (Sezonov, Joseleau-Petit, \& D'Ari, 2007) in the fermentation pots $(18 \mathrm{~mL}$ in $50 \mathrm{~mL})$, where cells are increasing in number, may also explain entry into the stationary phase of growth, although L. plantarum strains isolated from fermented maize porridges have been found to withstand low pH (2.5) (Kalui, Mathara, Kutima, Kiiyukia, \& Wongo, 2009). The absence of lag time could be influenced by several factors such as the inoculum quantity, the environmental conditions of the original and the new growth medium, the growth stage of the microorganisms during the time of inoculation (Ginovart, Prats, Portell, \& Silbert, 2011; Swinnen, Bernaerts, Dens, Geeraerd, \& Van Impe, 2004) and probably the investigation period. The L. plantarum strains and the yeasts were suspended in PBS at an active growth stage and inoculated into the maize slurry environment that had enough nutrients to support their growth. Also, enumeration after $6 \mathrm{~h}$ of fermentation would have given enough time for any adaptation by the inoculants. This adaptive nature is important for early and efficient production of the desired metabolic end product.

The microbial growth model estimated the growth rate of the individual microorganisms in the fermentation. Although variations were observed among the viable counts of the microorganisms with time, the mixed culture fermentation did not have any significant $(\mathrm{p} \leq 0.05)$ influence on the growth rates of the $L$. plantarum strains and yeasts except for $S$. boulardii SB20 in mixed fermentation with NGL5. This indicates the ability of the microorganisms to coexist in the fermentation, where each carries out its metabolic activities irrespective of the presence of the other. The growth of S. boulardii SB20 and C. tropicalis in the mixed culture fermentation, with $L$. plantarum strains at a low $\mathrm{pH} \leq 3.61$, also 
194 | Obinna-Echem et al.

Table 1: Lactic acid levels $\left(\mathrm{mmol} \mathrm{L}^{-1}\right)$ of ground maize slurries fermented with single and mixed cultures of Lactobacillus plantarum strains and yeasts

\begin{tabular}{|c|c|c|c|c|c|c|}
\hline \multirow[b]{2}{*}{ Sample } & \multicolumn{6}{|c|}{ Time (h) } \\
\hline & $0^{*}$ & 6 & 12 & 24 & 48 & 72 \\
\hline NGL5 & $5.99 \pm 0.13$ & $16.01 \pm 0.12^{a}$ & $43.70 \pm 0.83^{a}$ & $77.51 \pm 2.46^{a b c}$ & $101.94 \pm 1.90^{a}$ & $109.24 \pm 1.44^{a b}$ \\
\hline NGL5+NGY1 & $5.99 \pm 0.00$ & $14.13 \pm 0.49^{a b c}$ & $44.96 \pm 1.18^{a}$ & $77.54 \pm 2.25^{a b c}$ & $90.81 \pm 9.35^{a b c}$ & $100.05 \pm 11.96^{a b c}$ \\
\hline NGL5+SB20 & $6.11 \pm 0.06$ & $15.14 \pm 0.69^{a b}$ & $41.47 \pm 14.48^{a}$ & $73.89 \pm 5.51^{a b c}$ & $91.66 \pm 3.51^{a b c}$ & $86.92 \pm 3.01^{c}$ \\
\hline NGL7 & $6.00 \pm 0.25$ & $9.98 \pm 0.24 \mathrm{de}$ & $40.52 \pm 14.66^{a}$ & $82.93 \pm 13.66^{a}$ & $103.50 \pm 5.23^{a}$ & $120.09 \pm 3.39^{a}$ \\
\hline NGL7+NGY1 & $6.86 \pm 2.76$ & $11.66 \pm 0.36^{b c d}$ & $41.49 \pm 0.03^{a}$ & $72.39 \pm 4.02^{a b c}$ & $82.27 \pm 13.26^{b c}$ & $97.30 \pm 11.18^{a b}$ \\
\hline NGL7+SB20 & $6.04 \pm 0.21$ & $10.65 \pm 0.50^{c d}$ & $37.21 \pm 2.15^{a}$ & $63.88 \pm 5.43^{c}$ & $72.74 \pm 1.63^{c}$ & $84.57 \pm 6.34^{c}$ \\
\hline LpTx & $4.69 \pm 0.23$ & $11.24 \pm 0.42^{c d}$ & $36.98 \pm 0.43^{a}$ & $73.98 \pm 2.05^{a b c}$ & $100.51 \pm 0.50^{a b}$ & $110.63 \pm 6.12^{a b c}$ \\
\hline LpTx+NGY1 & $6.10 \pm 0.27$ & $10.69 \pm 0.63^{c d}$ & $37.63 \pm 2.42^{a}$ & $75.68 \pm 3.62^{a b c}$ & $90.48 \pm 11.61^{a b c}$ & $94.50 \pm 12.82^{a b}$ \\
\hline $\mathrm{LpTx}+\mathrm{SB} 20$ & $5.45 \pm 0.93$ & $8.42 \pm 4.05^{d e f}$ & $37.72 \pm 1.81^{a}$ & $66.84 \pm 0.25^{b c}$ & $80.77 \pm 8.55^{c}$ & $89.56 \pm 6.79^{b c}$ \\
\hline SB20 & $5.89 \pm 0.39$ & $5.29 \pm 0.62^{f g}$ & $10.69 \pm 0.28^{b}$ & $17.16 \pm 1.80^{d}$ & $20.23 \pm 3.81^{d}$ & $19.21 \pm 2.62^{d}$ \\
\hline NGY1 & $5.40 \pm 0.14$ & $6.75 \pm 0.20^{e f g}$ & $8.90 \pm 0.22^{b}$ & $13.89 \pm 0.32^{d}$ & $17.97 \pm 1.93^{d}$ & $17.80 \pm 3.38^{d}$ \\
\hline Control & $4.77 \pm 0.19$ & $4.75 \pm 0.28^{g}$ & $3.88 \pm 0.18$ & $2.86 \pm 0.63$ & $5.85 \pm 0.57$ & $6.53 \pm 0.52$ \\
\hline
\end{tabular}

* Values do not differ significantly

Values that share the same superscript in the same column do not differ significantly $(\mathrm{p} \leq 0.05)$. $\mathrm{N}=3 \pm \mathrm{SD}$

NGL5 \& NGL7 - Nigerian fermented maize L. plantarum strains and LpTx - commercial probiotic L. plantarum strain

NGY1 \& SB20 - Nigerian fermented maize C. tropicalis and probiotic S. boulardii SB20 respectively

Table 2: Glucose levels (mmol $\left.\mathrm{L}^{-1}\right)$ of ground maize slurries fermented with single and mixed cultures of Lactobacillus plantarum strains and yeasts

\begin{tabular}{|c|c|c|c|c|c|c|}
\hline \multirow[b]{2}{*}{ Sample } & \multicolumn{6}{|c|}{ Time $(\mathrm{h})$} \\
\hline & 0 & 6 & 12 & 24 & 48 & 72 \\
\hline NGL5 & $15.52 \pm 0.91^{e f g}$ & $41.50 \pm 0.46^{b c}$ & $43.14 \pm 0.94^{a b}$ & $37.28 \pm 1.55^{b}$ & $31.81 \pm 1.26^{a}$ & $29.63 \pm 0.30^{a}$ \\
\hline NGL5+NGY1 & $19.34 \pm 0.00^{\text {cde }}$ & $43.97 \pm 0.32^{b c}$ & $24.05 \pm 0.96^{\text {def }}$ & $2.74 \pm 1.39^{c}$ & - & - \\
\hline NGL5+SB20 & $27.69 \pm 1.20^{a}$ & $67.94 \pm 2.67^{a}$ & $14.52 \pm 5.93^{f}$ & - & - & - \\
\hline NGL7 & $15.24 \pm 0.87^{e f g}$ & $42.16 \pm 1.99^{b c}$ & $41.23 \pm 8.48^{b c}$ & $46.05 \pm 8.23^{a}$ & $32.08 \pm 2.5^{a}$ & $29.83 \pm 1.59^{a}$ \\
\hline NGL7+NGY1 & $17.62 \pm 0.86^{\text {cdef }}$ & $45.43 \pm 2.14^{b}$ & $33.02 \pm 0.50^{c d}$ & $2.75 \pm 1.10^{c}$ & - & - \\
\hline NGL7+SB20 & $25.25 \pm 1.41^{a b}$ & $60.34 \pm 2.17^{a}$ & $26.89 \pm 1.46^{d e}$ & - & - & - \\
\hline LpTx & $14.35 \pm 0.50^{f g}$ & $39.14 \pm 1.24^{b c}$ & $46.06 \pm 1.18^{a b}$ & $40.05 \pm 1.29^{a b}$ & $31.88 \pm 1.74^{a}$ & $26.88 \pm 2.04^{a}$ \\
\hline LpTx+NGY1 & $21.00 \pm 1.96^{b c}$ & $40.59 \pm 4.20^{b c}$ & $33.09 \pm 1.18^{c d}$ & $3.20 \pm 0.54^{c}$ & - & - \\
\hline LpTx+SB20 & $20.73 \pm 4.15^{c d}$ & $31.47 \pm 13.87^{c}$ & $22.36 \pm 0.94^{e f}$ & - & - & - \\
\hline SB20 & $12.26 \pm 0.61^{g}$ & $32.41 \pm 0.92^{c}$ & $18.95 \pm 0.51^{e f}$ & - & - & - \\
\hline NGY1 & $13.69 \pm 0.79^{f g}$ & $36.72 \pm 1.32^{b c}$ & $23.39 \pm 2.16^{\text {def }}$ & - & - & - \\
\hline Control & $16.56 \pm 0.26^{\text {defg }}$ & $39.57 \pm 0.64^{b c}$ & $52.48 \pm 1.06^{a}$ & $65.75 \pm 0.67$ & $80.12 \pm 8.86$ & $87.59 \pm 9.40$ \\
\hline
\end{tabular}

Values that share the same superscript in the same column do not differ significantly $(\mathrm{p} \leq 0.05)$. N=3土SD NGL5 \& NGL7 - Nigerian fermented maize L. plantarum strains and LpTx - commercial probiotic L. plantarum strain

NGY1 \& SB20 - Nigerian fermented maize C. tropicalis and probiotic S. boulardii SB20 respectively 
L. plantarum and C. tropicalis fermentation and antimicrobial activity $\mid 195$

Table 3: Fructose levels $\left(\mathrm{mmol} \mathrm{L}^{-1}\right)$ of ground maize slurries fermented with single and mixed cultures of Lactobacillus plantarum strains and yeasts

\begin{tabular}{lllllll}
\hline \multirow{2}{*}{ Sample } & \multicolumn{5}{c}{ Time $(\mathrm{h})$} \\
\cline { 2 - 7 } & 0 & 6 & 12 & 24 & 48 & 72 \\
\hline NGL5 & $9.23 \pm 0.30^{b c d}$ & $8.04 \pm 0.34^{a b}$ & $3.54 \pm 0.22^{d}$ & - & - & - \\
NGL5+NGY1 & $10.72 \pm 0.00^{a b}$ & $9.93 \pm 0.92^{a b}$ & - & - & - & - \\
NGL5+SB20 & $10.30 \pm 0.30^{a b c}$ & $10.44 \pm 0.53^{a}$ & - & - & - & - \\
NGL7 & $9.32 \pm 0.47^{b c d}$ & $9.22 \pm 0.42^{a b}$ & $5.41 \pm 2.13^{c d}$ & - & - & - \\
NGL7+NGY1 & $12.12 \pm 1.82^{a}$ & $9.93 \pm 0.60^{a b}$ & $6.02 \pm 0.09^{b c}$ & - & - & - \\
NGL7+SB20 & $10.14 \pm 0.26^{a b c}$ & $9.56 \pm 0.12^{a b}$ & - & - & - & - \\
LpTx & $8.62 \pm 0.26^{b c d}$ & $8.29 \pm 0.23^{a b}$ & $5.85 \pm 0.05^{b c}$ & - & - & - \\
LpTx+NGY1 & $10.20 \pm 0.54^{a b c}$ & $9.42 \pm 0.73^{a b}$ & $5.00 \pm 0.31^{c d}$ & - & - & - \\
LpTx+SB20 & $9.10 \pm 1.85^{b c d}$ & $7.20 \pm 3.22^{b}$ & $4.17 \pm 0.25^{c d}$ & - & - & - \\
SB20 & $8.33 \pm 0.54^{c d}$ & $7.94 \pm 0.61^{a b}$ & $3.81 \pm 0.63^{d}$ & - & - & - \\
NGY1 & $8.12 \pm 0.30^{c d}$ & $8.29 \pm 0.60^{a b}$ & $4.94 \pm 0.04^{c d}$ & - & - & $9.46 \pm 0.73$ \\
Control & $8.91 \pm 0.11^{b c d}$ & $7.67 \pm 0.30^{a b}$ & $8.94 \pm 0.06^{a}$ & $8.74 \pm 0.39$ & $9.03 \pm 1.25$ & 9.46 \\
\hline
\end{tabular}

Values that share the same superscript in the same column do not differ significantly $(\mathrm{p} \leq 0.05) . \mathrm{N}=3 \pm \mathrm{SD}$ NGL5 \& NGL7 - Nigerian fermented maize L. plantarum strains and LpTx - commercial probiotic L. plantarum strain

NGY1 \& SB20 - Nigerian fermented maize C. tropicalis and probiotic S. boulardii SB20 respectively

Table 4: Maltose levels $\left(\mathrm{mmol} \mathrm{L}^{-1}\right)$ of ground maize slurries fermented with single and mixed cultures of Lactobacillus plantarum strains and yeasts

\begin{tabular}{lllllll}
\hline \multirow{2}{*}{ Sample } & \multicolumn{5}{c}{ Time $(\mathrm{h})$} \\
\cline { 2 - 6 } & 0 & 6 & 12 & 24 & 48 & 72 \\
\hline NGL5 & $4.00 \pm 0.15^{a b}$ & $2.88 \pm 0.13^{\text {cde }}$ & - & - & - & - \\
NGL5+NGY1 & $3.56 \pm 0.00^{b}$ & $2.42 \pm 0.07^{\text {de }}$ & - & - & - & - \\
NGL5+SB20 & $4.03 \pm 0.19^{a b}$ & $2.56 \pm 0.18^{\text {de }}$ & - & - & - & - \\
NGL7 & $4.15 \pm 0.32^{a b}$ & $3.69 \pm 0.13^{a b c d e}$ & - & - & - & - \\
NGL7+NGY1 & $3.90 \pm 0.17^{a b}$ & $2.92 \pm 0.10^{\text {cde }}$ & - & - & - & - \\
NGL7+SB20 & $4.83 \pm 0.47^{a}$ & $3.62 \pm 1.14^{a b c d e}$ & - & - & - & - \\
LpTx & $4.54 \pm 0.38^{a b}$ & $3.71 \pm 0.26^{a b c d e}$ & - & - & - & - \\
LpTx+NGY1 & $4.29 \pm 0.18^{a b}$ & $3.13 \pm 0.29^{b c d e}$ & - & - & - & - \\
LpTx+SB20 & $4.14 \pm 0.80^{a b}$ & $2.27 \pm 1.16^{e}$ & - & - & - & - \\
SB20 & $4.39 \pm 0.27^{a b}$ & $4.29 \pm 0.14^{a b c}$ & - & - & - & - \\
NGY1 & $4.28 \pm 0.31^{a b}$ & $4.65 \pm 0.29^{a}$ & $2.12 \pm 0.18^{b}$ & - & - & - \\
Control & $4.78 \pm 0.16^{a b}$ & $4.46 \pm 0.26^{a b}$ & $4.30 \pm 0.07^{a}$ & $4.06 \pm 0.35$ & $3.92 \pm 0.36$ & $4.13 \pm 0.52$ \\
\hline
\end{tabular}

Values that share the same superscript in the same column do not differ significantly $(\mathrm{p} \leq 0.05)$. N=3土SD NGL5 \& NGL7 - Nigerian fermented maize L. plantarum strains and LpTx - commercial probiotic L. plantarum strain

NGY1 \& SB20 - Nigerian fermented maize C. tropicalis and probiotic S. boulardii SB20 respectively 
Table 5: Maltose levels (mmol $\mathrm{L}^{-1}$ ) of ground maize slurries fermented with single and mixed cultures of Lactobacillus plantarum strains and yeasts

\begin{tabular}{lllll}
\hline \multirow{2}{*}{ Sample } & \multicolumn{4}{c}{ Time $(\mathrm{h})$} \\
\cline { 2 - 5 } & 12 & 24 & 48 & 72 \\
\hline NGL5+SB20 & - & $18.31 \pm 5.23^{g h}$ & $14.32 \pm 2.12^{g h i}$ & $39.10 \pm 3.70^{\text {ef }}$ \\
NGL7+SB20 & - & $9.92 \pm 0.52^{g h i}$ & $18.83 \pm 1.37^{g h}$ & $53.20 \pm 10.54^{e}$ \\
LpTx+NGY1 & - & $14.8 \pm 1.06^{g h i}$ & - & - \\
LpTx+SB20 & $9.24 \pm 1.18^{g h i}$ & $16.87 \pm 2.03^{g h}$ & $10.25 \pm 2.54^{g h i}$ & $52.90 \pm 12.95^{e}$ \\
SB20 & $42.30 \pm 8.64^{e}$ & $91.37 \pm 6.39^{c}$ & $127.79 \pm 26.5^{b}$ & $194.00 \pm 24.7^{a}$ \\
NGY1 & - & $24.40 \pm 1.72^{f g}$ & $74.39 \pm 3.75^{d}$ & $77.50 \pm 4.14^{c d}$ \\
\hline
\end{tabular}

Values that share the same superscript do not differ significantly $(\mathrm{p} \leq 0.05) . \mathrm{N}=3 \pm \mathrm{SD}$

In all the samples no ethanol was detected after 0 and $6 \mathrm{~h}$ of fermentation

The NGL5, NGL5+NGY1, NGL7, NGL7+NGY1, LpTx and the control samples had no detectable ethanol levels

NGL5 \& NGL7 - Nigerian fermented maize L. plantarum strains and LpTx - commercial probiotic L. plantarum strain

NGY1 \& SB20 - Nigerian fermented maize $C$. tropicalis and probiotic $S$. boulardii SB20 respectively

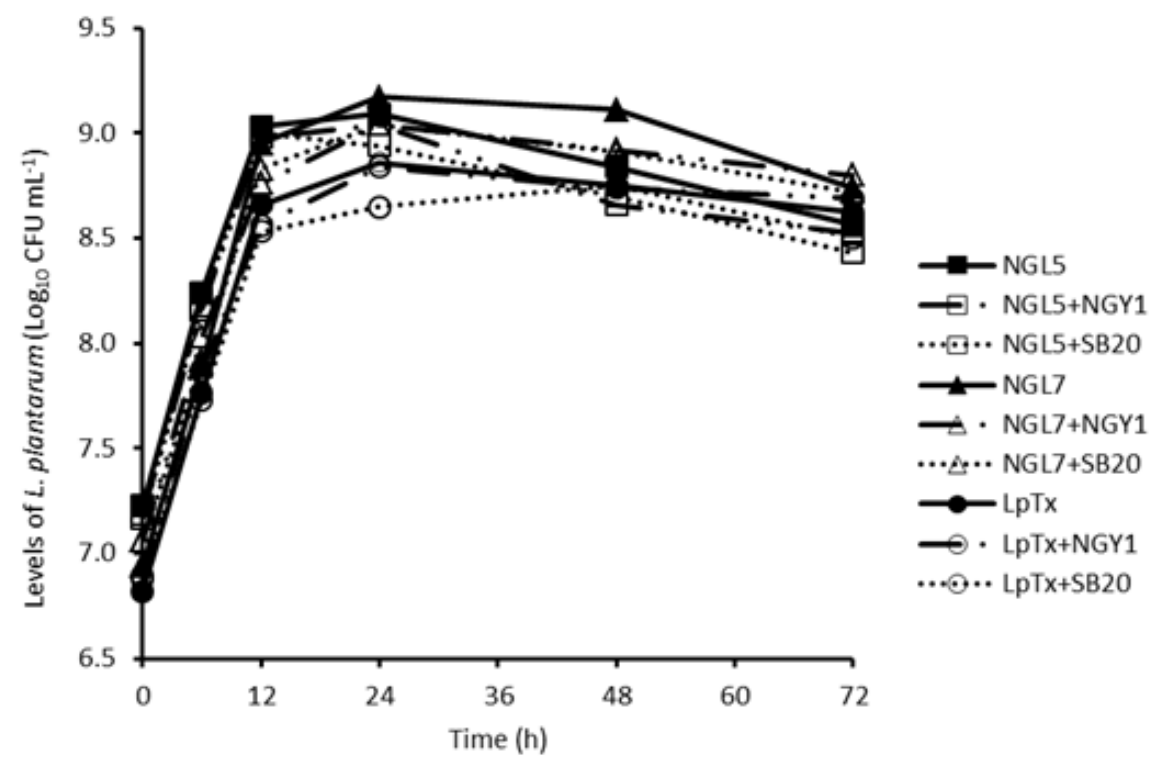

Figure 3: Levels $\left(\log _{10} \mathrm{CFU} \mathrm{mL}^{-1}\right)$ of Lactobacillus plantarum strains (NGL5, NGL7 and LpTx) in single or mixed culture fermentation of ground maize slurry with yeasts (Candida tropicalis - NGY1 and Saccharomyces boulardii SB20). 


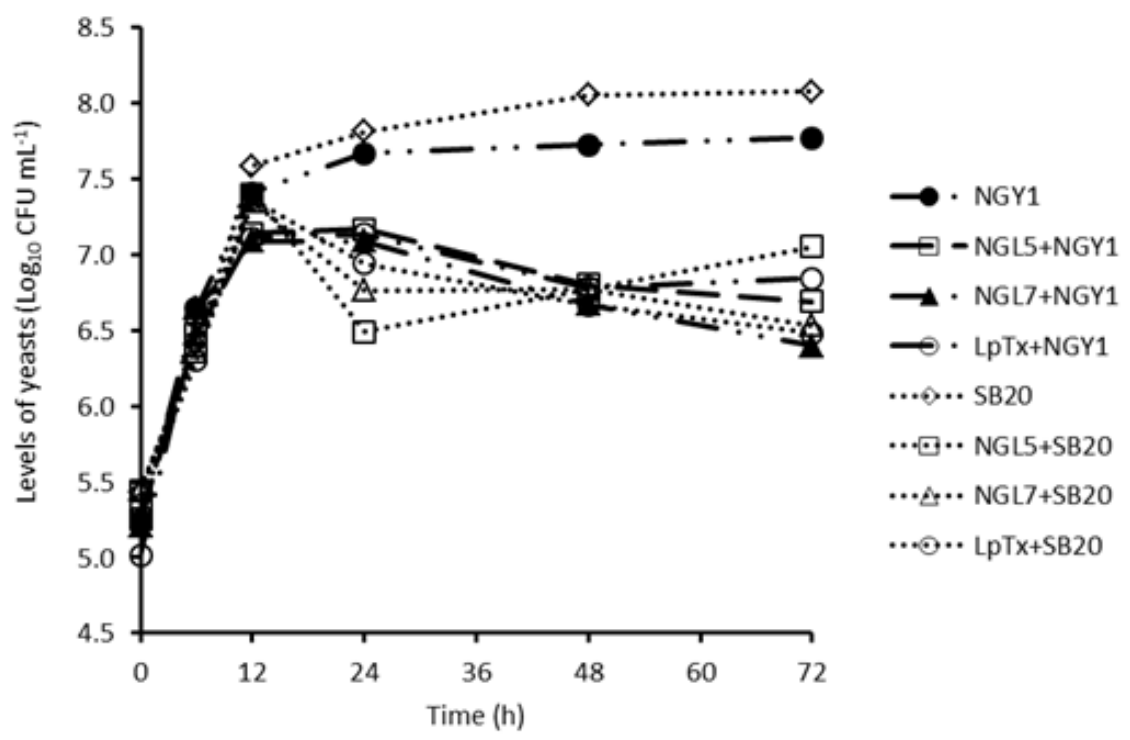

Figure 4: Levels $\left(\log _{10} \mathrm{CFU} \mathrm{mL}^{-1)}\right)$ of Candida tropicalis (NGY1) and Saccharomyces boulardii SB20 in single or mixed culture fermentation of ground maize slurry with Lactobacillus plantarum strains (NGL5, NGL7 and LpTx)

confirms the ability of these yeasts to tolerate the acid environment and suggests that they could be involved in some way in the cereal fermentation. The likely mechanism for the tolerance of a Candida species at low $\mathrm{pH}$ to lactic acid was explained by Halm, Hornbaek, Arneborg, SefaDedeh, and Jespersen (2004), while Omemu et al. (2007) documented the role of yeast in cereal and cereal-legume fermentation.

The Se(fit) indicated the total deviation of the observed values (viable counts) from the estimated model fit while the $\mathrm{R}^{2}$ statistics further elucidated how successful the fits were. Some curves were fitted well whilst others were not. The yeast single culture fermentation curve fit was $98 \%$, while the decrease in viable count after 12 and $48 \mathrm{~h}$ for $S$. boulardii SB20 and C. tropicalis respectively in the mixed culture fermentation affected the fit of their growth model curves, with $C$. tropicalis having $<89 \%$ and $S$. boulardii SB20 in mixed culture fermentation with NGL7 and LpTx having 77 and $70 \%$ respectively.

\subsection{Antimicrobial activity}

Table 6 shows the diameter of inhibition halos for $L$. plantrum strains and yeasts against the five relevant foodborne pathogens. The diameter of inhibition halos in the MRS agar varied from $10.6 \pm 0.2$ to $20.7 \pm 0.6 \mathrm{~mm}$ for $L$. monocytogenes NCTC 7973 and S. Enteritidis NCTC 5188 respectively. The inhibitory activity of the $L$. plantarum strains in the MRS agar against $B$. cereus NCIMB 11925, E. coli NCTC 11560, S. Enteritidis NCTC 5188, L. monocytogenes NCTC 7973 and $S$. aureus NCTC 3750 was mainly due to acidity as there was no inhibition recorded in the modified MRS media. This was in line with the report of Trias, Baneras, Badosa, and Montesinos (2008) that L. plantarum strains were without significant activity against $L$. monocytogenes and S. aureus in MRS, with $90 \%$ reduced glucose. $S$. boulardii antagonistic ability had mainly been observed in vitro and demonstrated that the prevention of $\mathrm{C}$. difficile and $\mathrm{V}$. cholerae associated infection is through the production of an antimicrobial proteolytic enzyme (Murphy \& Kavanagh, 1999; Tasteyre, Barc, Karjalainen, 
198 | Obinna-Echem et al.

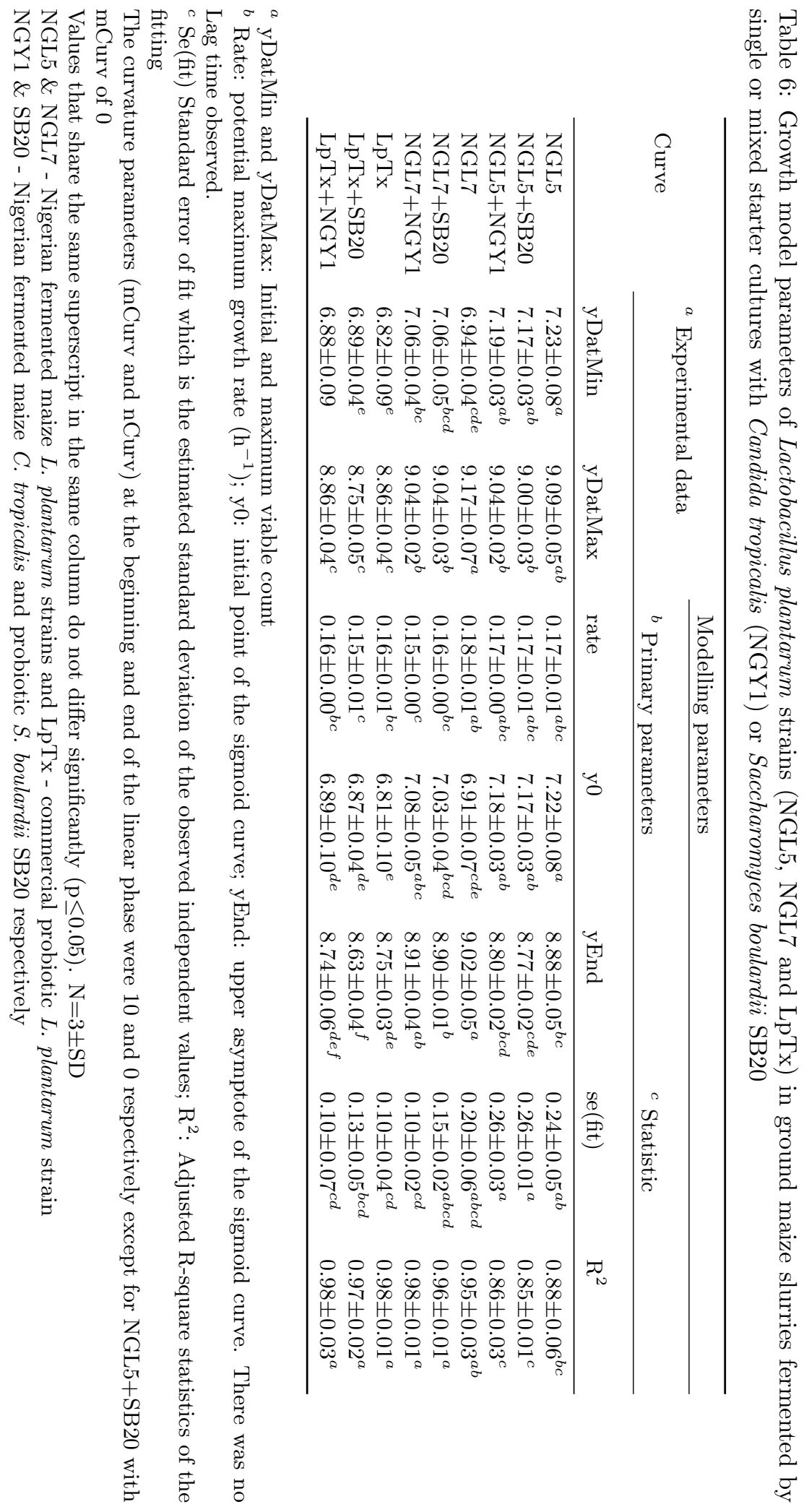

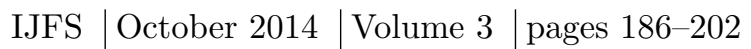



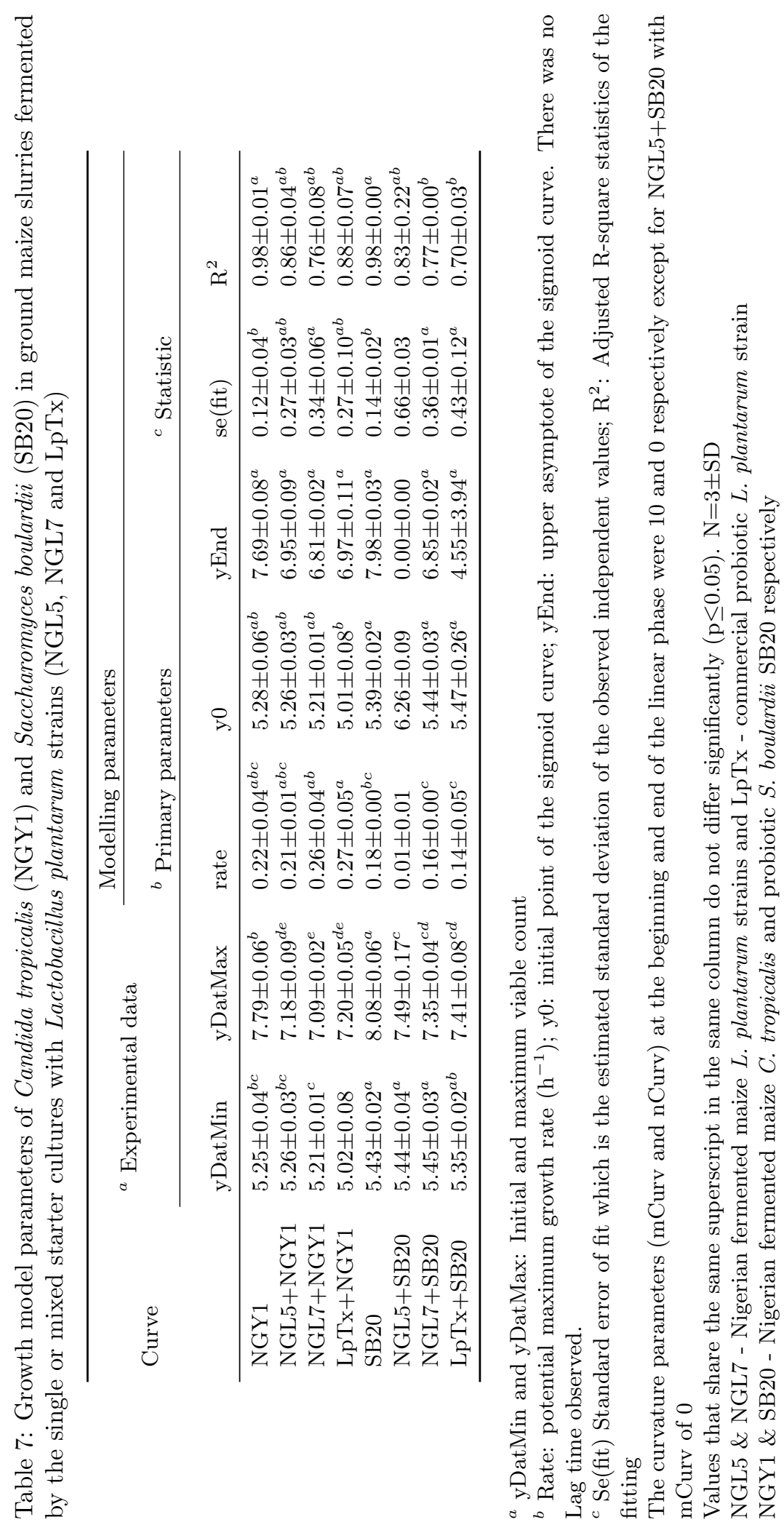

IJFS | October $2014 \mid$ Volume $3 \mid$ pages 186-202 
Bourlioux, \& Collignon, 2002). Pathogen inhibition on agar plates by yeasts in this present study is quite unique as reports of such are scarce in the literature. S. bourladii SB20 was more inhibitory towards L. monocytogenes NCTC 7973 and B. cereus NCIMB 11925 than $C$. tropicalis in malt extract agar was. S. aureus NCTC 3750 was resistant to both yeasts. The inhibitory mechanisms, whilst unclear, could be attributed mainly to ethanol production. S. boulardii SB20 in this study had maximum lactic acid and ethanol concentrations of 20.23 and $194 \mathrm{mmol} \mathrm{L}^{-1}$ respectively during the fermentation of sterile ground maize slurry. However, the review by Shetty and Jespersen (2006) indicated that the antagonistic property of $S$. cerevisiae was mostly due to the polysaccharide part of the cell wall that is involved in surface binding of pathogenic toxins. C. tropicalis (NGY1) in this fermentation experiment did not produce a significant amount of ethanol, neither was there a significant decrease in $\mathrm{pH}$ for antimicrobial activity. It was not surprising, therefore, that $C$. tropicalis (NGY1) had no inhibitory effect against the pathogen.

\section{Conclusions}

The L. plantarum strains, either as single or mixed starter cultures with yeasts, demonstrated strong fermentation ability, with significant reduction in $\mathrm{pH}$, and were inhibitory against foodborne pathogens which is vital in the use of selected organisms as starters for the safety of products. Although, C. tropicalis was less inhibitory to the pathogens, its ability to grow in the fermentation with little or no ethanol production could be preferred in its use as a mixed starter culture with the LAB in the production of infant complimentary foods. The study also demonstrated that the ground maize slurry could act as a vehicle to relay probiotics in akamu production.

\section{Acknowledgements}

The authors acknowledge the financial support from the Rivers State Scholarship Board, Rivers State Nigeria. They also appreciate the technical assistance of technicians in the Microbiol- ogy unit of Plymouth University, UK: Matthew Emery who kindly provided the pathogens, Sarah Jamieson for her assistance with media preparations and William Vevers for support in running the HPLC equipment.

\section{References}

Aidoo, K., Nout, M., \& Sarkar, P. (2006). Occurrence and function of yeasts in asian indigenous fermented foods. Fems Yeast Research, 6(1), 30-39. doi:10.1111/j.15671364.2005.00015.x

Akinrele, I. (1970). Fermentation studies on maize during the preparation of a traditional african starch-cake food. Journal of the Science of Food and Agriculture, 21 (12), 619-625.

Annan, N., Poll, L., Sefa-Dedeh, S., Plahar, W., \& Jakobsen, M. (2003). Volatile compounds produced by Lactobacillus fermentum, Saccharomyces cerevisiae and Candida krusei in single starter culture fermentations of ghanaian maize dough. Journal of Applied Microbiology, 94(3), 462-474. doi:10.1046/j.1365-2672.2003.01852.x

Banigo, E. O. I. \& Muller, H. G. (1972). Manufacture of ogi (a nigerian fermented cereal porridge) - comparative evaluation of corn, sorghum and millet. Canadian Institute of Food Science and Technology JournalJournal de L'Institut Canadien de Science et Technologie Alimentaires, 5(4), 217-221.

Baranyi, J. \& Roberts, T. A. (1994). A dynamic approach to predicting bacterial-growth in food. International Journal of Dairy Technology, 23(3-4), 277-294. doi:10 . 1016/ 0168-1605(94)90157-0

Edema, M. O. \& Sanni, A. I. (2008). Functional properties of selected starter cultures for sour maize bread. Food Microbiology, 25(4), 616-625. doi:10.1016/j . fm. 2007. 12.006

Farthing, M., Salam, M. A., Lindberg, G., Dite, P., Khalif, I., Salazar-Lindo, E., ... LeMair, A. (2013). Acute diarrhea in adults and children: a global perspective. World Gastroenterology Organisation Global Guidelines. Retrieved from http:// 
L. plantarum and C. tropicalis fermentation and antimicrobial activity $\mid 201$

www . worldgastroenterology . org / assets / export / userfiles / Acute\% 20Diarrhea_long_ FINAL_120604.pdf

Ginovart, M., Prats, C., Portell, X., \& Silbert, M. (2011). Exploring the lag phase and growth initiation of a yeast culture by means of an individual-based model. Food Microbiology, 28(4, SI), 810-817. 6th International Conference of Predictive Modeling in Foods (6ICPMF), Washington, DC, SEP 08-12, 2009. doi:10.1016/j.fm.2010.05.004

Gobbetti, M. \& Corsetti, A. (1997). Lactobacillus sanfrancisco a key sourdough lactic acid bacterium: a review. Food Microbiology, 14(2), 175-187. doi:10.1006 / fmic. 1996. 0083

Halm, M., Hornbaek, T., Arneborg, N., SefaDedeh, S., \& Jespersen, L. (2004). Lactic acid tolerance determined by measurement of intracellular ph of single cells of candida krusei and saccharomyces cerevisiae isolated from fermented maize dough. International Journal of Dairy Technology, 94(1), 97-103. doi:10.1016/j.ijfoodmicro. 2003.12.019

Holzapfel, W. (2002). Appropriate starter culture technologies for small-scale fermentation in developing countries. International Journal of Dairy Technology, 75 (3, SI), 197212. Annual Meeting of the Institute-ofFood-Technologists, Kempthall, Switzerland, 1999. doi:10.1016/S0168-1605(01) 00707-3

Kalui, C. M., Mathara, J. M., Kutima, P. M., Kiiyukia, C., \& Wongo, L. E. (2009). Functional characteristics of Lactobacillus plantarum and Lactobacillus rhamnosus from ikii, a kenyan traditional fermented maize porridge. African Journal of Biotechnology, 8(18), 4363-4373.

Kunene, N., Hastings, J., \& von Holy, A. (1999). Bacterial populations associated with a sorghum-based fermented weaning cereal. International Journal of Dairy Technology, 49(1-2), 75-83. doi:10.1016 / S01681605(99)00062-8

Lee, C.-H. (2009). Food biotechnology (In G. Campbell-Platt, Ed.). Food Science and Technology. Oxford, UK: Blackwell Publishing Ltd.
Leroi, F. \& Pidoux, M. (1993). Characterization of interactions between lactobacillushilgardii and saccharomyces-florentinus isolated from sugary kefir grains. Journal of Applied Bacteriology, 74(1), 54-60. doi:10.1111/j.1365-2672.1993.tb02996.x

Majhenic, A. C., Lorberg, P. M., \& Rogelj, I. (2007). Characterisation of the Lactobacillus community in traditional karst ewe's cheese. International Journal of Dairy Technology, 60(3), 182-190.

Miles, A., Misra, S., \& Irwin, J. (1938). The estimation of the bactericidal power of the blood. Journal of Hygiene, 38(6), 732-749.

Motarjemi, Y. (2002). Impact of small scale fermentation technology on food safety in developing countries. International Journal of Dairy Technology, 75 (3, SI), 213-229. Annual Meeting of the Institute-of-FoodTechnologists, KEMPTHALL, SWITZERLAND, 1999. doi:10.1016/S0168-1605(01) 00709-7

Mugula, J., Narvhus, J., \& Sorhaug, T. (2003). Use of starter cultures of lactic acid bacteria and yeasts in the preparation of togwa, a tanzanian fermented food. International Journal of Dairy Technology, 83(3), 307318. doi:10.1016/S0168-1605(02)00386-0

Murphy, A. \& Kavanagh, K. (1999). Emergence of saccharomyces cerevisiae as a human pathogen implications for biotechnology. Enzyme and Microbial Technology, 25(7), 551-557. doi:10 . 1016 / S0141 - 0229(99) $00086-1$

Muyanja, C., Narvhus, J., Treimo, J., \& Langsrud, T. (2003). Isolation, characterisation and identification of lactic acid bacteria from bushera: a ugandan traditional fermented beverage. International Journal of Dairy Technology, 80(3), 201-210. doi:10.1016/S0168-1605(02)00148-4

Nguyen, T. T. T., Loiseau, G., Icard-Verniere, C., Rochette, I., Treche, S., \& Guyot, J.-P. (2007). Effect of fermentation by amylolytic lactic acid bacteria, in process combinations, on characteristics of rice/soybean slurries: a new method for preparing high energy density complementary foods for young children. Food Chem- 
istry, 100(2), 623-631. doi:10.1016 / j . foodchem.2005.09.080

Niven, S., Beal, J., \& Brooks, P. (2004). The simultaneous determination of short chain fatty acid, monosaccharides and ethanol in fermented liquid pig diets. Animal Feed Science and Technology, 117(3-4), 339345. doi:10.1016/j.anifeedsci.2004.09.003

Nyatoti, V., Mtero, S., \& Rukure, G. (1997). Pathogenic escherichia coli in traditional african weaning foods. Food Control, 8(1), 51-54. doi:10.1016/S0956-7135(96)00068-0

Obinna-Echem, P. C., Kuri, V., \& Beal, J. (2014). Evaluation of the microbial community, acidity and proximate composition of akamu, a fermented maize food. Journal of The Science of Food and Agriculture, 94(2), 331-340. doi:10.1002/jsfa.6264

Omemu, A. M., Oyewole, O. B., \& Bankole, M. O. (2007). Significance of yeasts in the fermentation of maize for ogi production. Food Microbiology, 24(6), 571-576. doi:10. 1016/j.fm.2007.01.006

Ouoba, L. I. I., Diawara, B., Jespersen, L., \& Jakobsen, M. (2007). Antimicrobial activity of Bacillus subtilis and Bacillus pumilus during the fermentation of african locust bean (parkia biglobosa) for Soumbala production. Journal of Applied Microbiology, 102(4), 963-970. doi:10.1111/j.1365-2672. 2006.03156.x

Reddy, G., Altaf, M., Naveena, B. J., Venkateshwar, M., \& Kumar, E. V. (2008). Amylolytic bacterial lactic acid fermentation - a review. Biotechnology Advances, 26(1), 2234. doi:10.1016/j.biotechadv.2007.07.004

Sezonov, G., Joseleau-Petit, D., \& D'Ari, R. (2007). Escherichia coli physiology in luriabertani broth. Journal of Bacteriology, 189(23), 8746-8749. doi:10 . 1128/ JB . 01368-07

Shetty, P. \& Jespersen, L. (2006). Saccharomyces cerevisiae and lactic acid bacteria as potential mycotoxin decontaminating agents. Trends in Food Science \& Technology, 17(2), 48-55. doi:10.1016/j.tifs.2005.10. 004

Swinnen, I., Bernaerts, K., Dens, E., Geeraerd, A., \& Van Impe, J. (2004). Predictive modelling of the microbial lag phase: a review.
International Journal of Dairy Technology, 94(2), 137-159. doi:10.1016/j.ijfoodmicro. 2004.01.006

Tasteyre, A., Barc, M., Karjalainen, T., Bourlioux, P., \& Collignon, A. (2002). Inhibition of in vitro cell adherence of clostridium difficile by saccharomyces boulardii. Microbial Pathogenesis, 32(5), 219-225. doi:10.1006/mpat.2002.0495

Teniola, O. \& Odunfa, S. (2001). The effects of processing methods on the levels of lysine, methionine and the general acceptability of ogi processed using starter cultures. International Journal of Dairy Technology, 63(1-2), 1-9. doi:10.1016/S0168-1605(00) 00321-4

Teniola, O. \& Odunfa, S. (2002). Microbial assessment and quality evaluation of ogi during spoilage. World Journal of Microbiology \& Biotechnology, 18(8), 731-737. doi:10.1023/A:1020426304881

Towo, E., Matuschek, E., \& Svanberg, U. (2006). Fermentation and enzyme treatment of tannin sorghum gruels: effects on phenolic compounds, phytate and in vitro accessible iron. Food Chemistry, 94(3), 369-376. doi:10.1016/j.foodchem.2004.11.027

Trias, R., Baneras, L., Badosa, E., \& Montesinos, E. (2008). Bioprotection of golden delicious apples and iceberg lettuce against foodborne bacterial pathogens by lactic acid bacteria. International Journal of Dairy Technology, 123(1-2), 50-60. doi:10.1016/ j.ijfoodmicro.2007.11.065

Wakil, S. M., Onilude, A. A., Adetutu, E. M., \& Ball, A. S. (2008). PCR-DGGE fingerprints of microbial successional changes during fermentation of cereal-legume weaning foods. African Journal of Biotechnology, 7(24), 4643-4652. 